\title{
Exam Phobia in Government High School Students, Guntur, Andhra Pradesh, India SankaraPitchaiahPodila ${ }^{1}$,Anjani Thottempudi ${ }^{2}$ \\ ${ }^{1}$ Department of Geology, AcharyaNagarjuna University, Andhra Pradesh, India ${ }^{2}$ Villa 24, Green Park City, Visakhapatnam, Andhra Pradesh, India \\ *Corresponding author email-lifeskillssankar@gmail.com
}

\section{ABSTRACT}

Phobias are common in human life. Some of the most common phobias are exam phobia in students, acrophobia (fear of heights), achluophobia (fear of darkness), hemophobia (fear of blood), fear of journey etc. The present study was carried out to know the extent of the exam phobia among $8^{\text {th }}$ to $10^{\text {th }}$ studying students in rural and urban schools. The response was taken from 3399 students ( $\left.8^{\text {th }}: 1175,9^{\text {th }}: 1095,10^{\text {th }}: 1129\right)$. The study found that the phobia was more in $10^{\text {th }}$ class students compared to $8^{\text {th }}$ and $9^{\text {th }}$ classes. Homeopathy, Exposure based therapy, Cognitive therapy and Relaxation techniques are some of the useful treatment methods. The authors suggested to follow the given exam preparation tips to reduce exam phobia.

Keywords :Exam Phobia, Anxiety, Treatment, Tips for Exam Preparation, Rural and Urban Students

\section{INTRODUCTION}

The American Psychiatric Association identifies three different categories of phobia: social phobia, agoraphobia, and specific phobia. When people talk about having a phobia of a specific object, they are referring to a specific phobia (https:// www.verywellmind.com). Exam phobia is one type of specific phobia. A Phobia can have a serious impact on well-being.

The incidence of exam anxiety has risen from $27 \%$ in 2009 to almost 40\% in 2010 (Mohapatra et al., 2012). Sufiana and Farhat (2015) were made an effort to measure secondary school level students' views about the phobia of examination and identified problems and causes of examination phobia among female students of secondary level. The findings of the study reported that phobia of examination affects the academic performance of the students in the examination and they could not perform according to their knowledge due to a phobia of examination as they forget the answers to some questions during examination due to nervousness and a phobia of examination. A significant number of students answered their mind go blank before the start of the examination and they could not depict their knowledge on paper due to limited time pressure allowed for paper. de Oliveira-Souza (2018) felt that phobia is Supernatural and distinct, but poorly recognized specific phobia with an adverse impact on daily living.

Exam phobia is an irrational phobia that leads to avoidance of the phobia situation or object which in turn increases the severity of the phobia. The students have an excessive and unreasonable phobia due to exam or the presence or anticipation of a horrible situation causes an anxiety. The sufferer realizes that the phobia is irrational; and the avoidance or distress due to the stimuli causes impairment in functioning (Javed and Khan, 2011). 
A high level of anxiety from exam phobia may suffer from panic disorder amongst students. The students feel uneasiness, helplessness and severe stress (Watson and Friend, 1969). Some students become so frightened that they cannot perform well in the examination, even they forget the answers of the questions as they enter in the examination hall (Stellar, 2009). Anxiety disorders are prevalent in the students and can have a destructive influence on students' lives. According to Shashank (2008), more than 50 per cent of students suffer from an examination phobia. Almost all the students worry about forgetting in an exam, not being able to recall essential information during solving paper. Kumari and Jain (2014) identified the reasons for stress in college students. Some of the phobias are listed below.

\section{LIST OF SOME PHOBIAS}

\begin{tabular}{|l|l|}
\hline Achluophobia & Phobia of darkness \\
\hline Acrophobia & Phobia of heights \\
\hline Agoraphobia & Phobia of open spaces or crowds \\
\hline Anthrophobia & Phobia of flowers \\
\hline Astraphobia & Phobia of thunder and lightning \\
\hline Atychiphobia & Phobia of failure \\
\hline Autophobia & Phobia of being alone \\
\hline Claustrophobia & Phobia of confined spaces \\
\hline
\end{tabular}

\begin{tabular}{|l|l|}
\hline Glossophobia & Phobia of speaking in public \\
\hline Hemophobia & Phobia of blood \\
\hline Hydrophobia & Phobia of water \\
\hline Necrophobia & Phobia of death or dead things \\
\hline Somniphobia & Phobia of sleep \\
\hline Zoophobia & Phobia of animals \\
\hline
\end{tabular}

The present study was carried out to know the extent of the exam phobia among the students studying in rural and urban schools.

\section{METHODOLOGY}

$8^{\text {th }}$ to $10^{\text {th }}$ class students were chosen as subjects. A total of 3399 students was participated and out of them 1175 are studying $8^{\text {th }}, 1095$ are 9 th and 1129 are 10 th class. 1342 were studied in seven rural schools and 2057 in seven urban schools. Details are shown in Table 1. Students were assembled in a classroom of the respective schools and asked them to give their response to a single question-"Do you have an exam phobia ?". The purpose of the study and the details regarding the phobia were explained in their mother tongue. The response was analyzed using statistical analysis. Percent variation was observed and presented under results and discussion.

Table 1 Class Wise Student's Strength

\begin{tabular}{|c|c|c|c|c|c|c|c|c|c|c|c|c|c|}
\hline \multicolumn{9}{|c|}{ Rural Schools } & \multicolumn{7}{|c|}{ Urban Schools } \\
\hline Sch* & $\mathbf{8 t h}$ & $\mathbf{A}$ & $\mathbf{9 t h}$ & $\mathbf{B}$ & $\mathbf{1 0 t h}$ & $\mathbf{C}$ & Sch $^{* *}$ & $\mathbf{8 t h}$ & $\mathbf{D}$ & $\mathbf{9 t h}$ & $\mathbf{E}$ & $\mathbf{1 0 t h}$ & F \\
\hline 1 & 59 & 14 & 56 & 8 & 49 & 23 & 1 & 173 & 61 & 159 & 31 & 189 & 111 \\
\hline 2 & 30 & 12 & 21 & 10 & 30 & 13 & 2 & 66 & 22 & 89 & 27 & 77 & 29 \\
\hline 3 & 97 & 39 & 96 & 41 & 86 & 60 & 3 & 130 & 37 & 93 & 35 & 93 & 40 \\
\hline 4 & 92 & 25 & 78 & 26 & 86 & 45 & 4 & 100 & 36 & 94 & 55 & 116 & 52 \\
\hline 5 & 64 & 28 & 47 & 24 & 47 & 38 & 5 & 92 & 27 & 83 & 39 & 77 & 34 \\
\hline 6 & 49 & 30 & 57 & 35 & 49 & 44 & 6 & 51 & 18 & 77 & 32 & 53 & 32 \\
\hline 7 & 79 & 8 & 69 & 8 & 101 & 45 & 7 & 93 & 47 & 76 & 31 & 76 & 24 \\
\hline
\end{tabular}

* Sch: School, 1- Chinakakani, 2- Namburu girls', 3- Namburu, 4- Ponnekallu,5- Takkellapadu, 6- Tadikonda girls', 7- Venigalla

A,B,C, D,E,F- No. of students with Exam Phobia

**Sch: School, 1-SK, 2-SGNKR, 3-SJRR, 4-SKS, 5-P, 6-KSR, 7-SCMP 


\section{RESULTS AND DISCUSSION}

A percent variation of the rural and urban students, those suffering from exam phobia was shown in tables 2 and 3 and figures 1 and 2 and is explained below.

\section{Rural Schools}

$8^{\text {th }}$ class

Highest percent of Tadikonda girls' school (61.22) were marked the exam phobia, followed by Takkellapadu (43.75\%) and Namburu (40.21\%). The lowest percent was noticed with Venigallaschool (10.13\%).

\section{$9^{\text {th }}$ Class}

$61.40 \%$ of Tadikonda school students had expressed the exam phobia, followed by Takkellapadu school students (51.06\%) and Namburu girls' (47.62\%). Comparatively, the problem is low in Venigalla (11.59) and Namburu girls (14.29\%).

\section{$10^{\text {th }}$ Class}

Highest percent of Tadikonda girls' students (89.80) were marked the of exam phobia, followed by Takkellapadu (80.85\%) and Namburu (69.77\%). The problem is low in Namburu girls' (43.33\%).

As the $10^{\text {th }}$ class marks/grades are important for future studies, most of the students feel tense from the beginning of the academic year. As such, the percentages are abnormally high, for ex., 89.80 in the case of Tadikonda girls' and the lowest is 43.33 (Namburu girls').
TABLE 2 EXAM PHOBIA AMONG RURAL SCHOOL STUDENTS*

\begin{tabular}{|l|l|l|l|}
\hline Exam phobia & 8th & 9th & 10th \\
\hline Chinakakani & 23.73 & 14.29 & 46.94 \\
\hline $\begin{array}{l}\text { Namburu } \\
\text { girls' }\end{array}$ & 40.00 & 47.62 & 43.33 \\
\hline Namburu & 40.21 & 42.71 & 69.77 \\
\hline Ponnekallu & 27.17 & 33.33 & 52.33 \\
\hline Takkellapadu & 43.75 & 51.06 & 80.85 \\
\hline $\begin{array}{l}\text { Tadikonda } \\
\text { girls' }\end{array}$ & 61.22 & 61.40 & 89.80 \\
\hline Venigalla & 10.13 & 11.59 & 44.55 \\
\hline
\end{tabular}

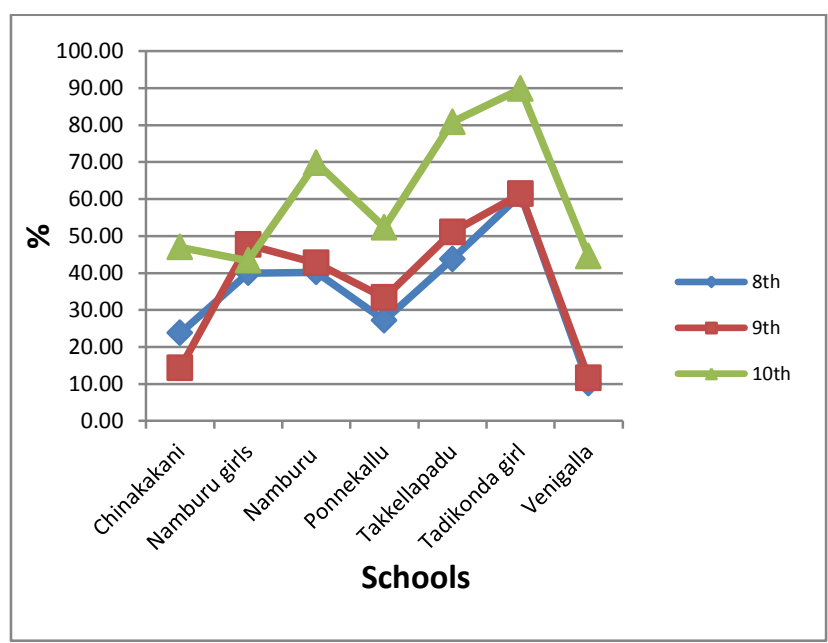

Figure 1.Percent variation of Exam Phobia in rural school students

\section{Urban Schools}

$8^{\text {th }}$ Class

$50.54 \%$ of SCMP students were pointed exam phobia, followed by SKS (36.00\%) and KSR (35.29\%). The lowest percent was observed with SJRR (28.46\%).

\section{$9^{\text {th }}$ Class}

Highest percent of SKR (58.51) school students had exam phobia, followed by $\mathrm{P}(46.99 \%)$ and KSR (41.56\%). The lowest percent was observed in SK students (19.50\%). 
$10^{\text {th }}$ Class

$60.38 \%$ of KSR students were suffering from exam phobia, followed by SK (58.73\%) and SKS (44.83\%). The lowest percent was observed in SCMP (31.58\%).

TABLE 3 EXAM PHOBIA AMONG URBAN SCHOOL STUDENTS

\begin{tabular}{|l|l|l|l|}
\hline $\begin{array}{l}\text { Exam } \\
\text { phobia }\end{array}$ & 8th & 9th & 10th \\
\hline SK & 35.26 & 19.50 & 58.73 \\
\hline SGNKR & 33.33 & 30.34 & 37.66 \\
\hline SJRR & 28.46 & 37.63 & 43.01 \\
\hline SKS & 36.00 & 58.51 & 44.83 \\
\hline P & 29.35 & 46.99 & 44.16 \\
\hline KSR & 35.29 & 41.56 & 60.38 \\
\hline SCMP & 50.54 & 40.79 & 31.58 \\
\hline
\end{tabular}

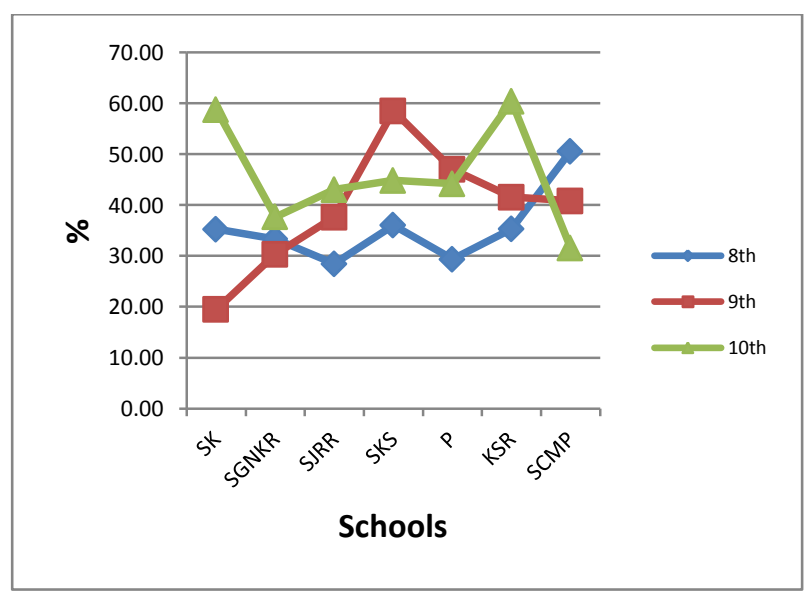

Figure 2.Percent variation of Exam Phobia in urban school students

\section{Comparative study}

\section{Rural schools}

Comparison of exam phobia among $8^{\text {th }}$ to $10^{\text {th }}$ class rural and urban students was shown in table 4 and figure 3). Among the rural schools, high percent of Namburu students (24.31) had exam phobia followed by Tadikonda girls' (18.92\%), Ponnekallu (16.67\%) and Takkella- padu (15.63\%). The lowest percent was observed with Nambur girls' (6.08\%).

\section{Urban schools}

In the case of urban schools, high percent of SK students (24.76) had an exam phobia (Table 4 and Figure 4), followed by SKS (17.44\%), SJRR (13.66\%) and SCMP (12.44\%). The lowest percent was observed with SGNKR (9.51\%).

TABLE 4 COMPARATIVE STUDY OF EXAM PHOBIA BETWEEN RURAL AND URBAN SCHOOL STUDENTS

\begin{tabular}{|l|c|c|l|}
\hline \multicolumn{2}{|c|}{ Rural Schools (\%) } & \multicolumn{2}{c|}{ Urban Schools (\%) } \\
\hline Chinakakani & 7.81 & 24.76 & SK \\
\hline Namburu girls' & 6.08 & 9.51 & SGNKR \\
\hline Namburu & 24.31 & 13.66 & SJRR \\
\hline Ponnekallu & 16.67 & 17.44 & SKS \\
\hline Takkellapadu & 15.63 & 12.20 & P \\
\hline $\begin{array}{l}\text { Tadikonda } \\
\text { girls' }\end{array}$ & 18.92 & 10.00 & KSR \\
\hline Venigalla & 10.59 & 12.44 & SCMP \\
\hline
\end{tabular}

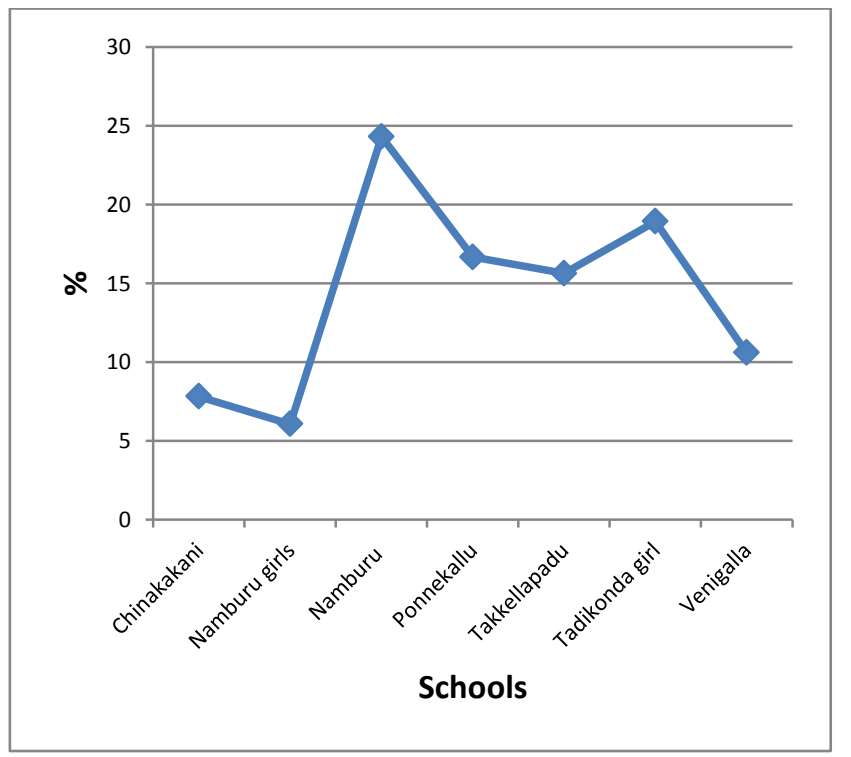

Figure 3. Comparison within the rural school students 


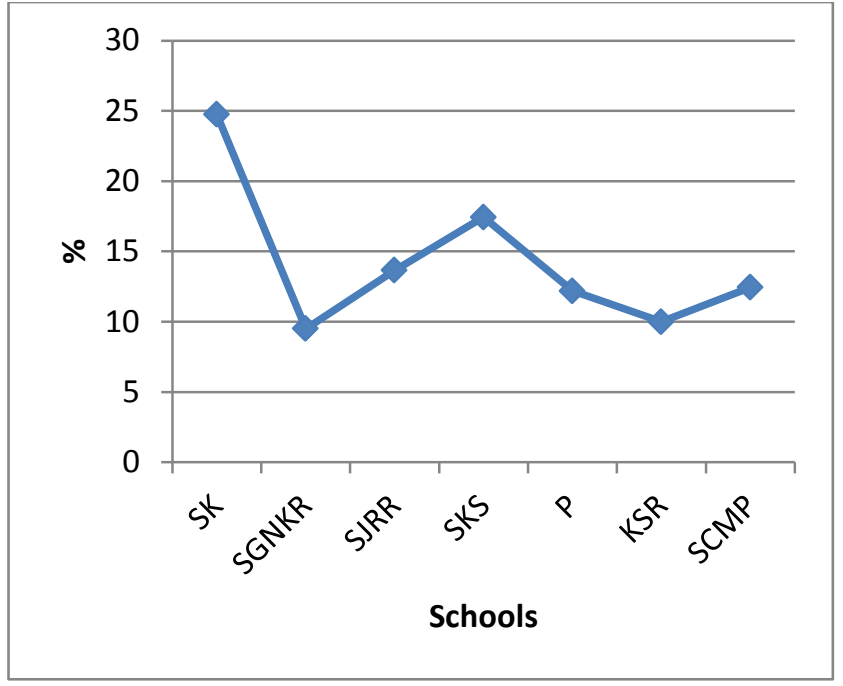

Figure 4. Comparison within the Urban school students

Cassady (2001) found that phobia and anxiety affect the mind and threat physically or psychologically. Stellar (2009) illustrated that the students suffering from exam phobia postpone enjoyment oriented activities. They don't like to go to playground and cancel their picnic schedules too. They remain busy with their books willy-nilly. They go on reading without understanding while sipping a cup of tea or coffee. They go on revising while lying down in their beds.

\section{Treatment Methods}

Various researchers had suggested different methods for the treatment of exam phobia.

Examination stress is better prevented than treated. A systematic, persistent, organized, planned and regular effort from the beginning of the academic session is the best method for any adolescent to prevent anxiety related to the examination. Finally, it should be noted that some children handle all situations coolly, while others start panicking with even a small problem at hand. Hence, it is very necessary that parents should always encourage their children and keep them busy with other extracurricular activities like music, dance, sports, etc. and also help as stress busters (Mohapatra et al., 2012).

It is important to remember that you are not alone. Phobias are common, but also treatable. If you believe that you have the symptoms of some type of phobia, consult your doctor for further evaluation and treatment advice (https://www.verywellmind.com).

Students may be given frequent tests so that they may take the examination as routine work. A healthy competitive environment among their students within the class may be promoted, where position loser is not humiliated, remedial teaching may be provided to low achievers in their class in order to minimize the phobia of failing in final examination. Parents should encourage their children to better performance in the exams (Khatoon and Farhat, 2015). Chawla et al., (2013) felt that the phobia of the examination affects the efficiency and feelings of the students. The study found several obstacles faced by students, such as time pressure, annoyance of teachers on poor performance, over expectations of the parents and punishment from them, forgetting the answers after seeing the question papers, etc.

According to Hanies et al., (2007), Cognitive Behavioral Therapy (CBT) has been found to significantly decrease phobic symptoms by helping the phobia sufferer change his or her way of thinking. Most of the individuals who are treated for phobia and other anxiety disorders feel significant improvement and enjoyment in life. A variety of treatment options are available including Cognitive Behavioral Therapy (CBT), Exposure Therapy, Anxiety Management, Relaxation Techniques, and Medications. Hoffman and Weghorst (1997) stated that one or a combination of these may be recommended according to the situation and intensity. No any single treatment is sufficient. If anyone may be suitable for one person perhaps it may not be the best choice for someone else. 
Smita (2009) expressed that the most important technique to remove or minimize the exam phobia is to study well. Most of the students don't prepare well enough for exams. The best strategy is to start preparations early keeping in mind a general idea of the course and the major points of all the subjects before starting exams, They should not awake up all night before the exam even if they have lots of studying left to do.

\section{Some of the useful methods}

Exposure-based therapy - (Singh and Singh, 2016) Cognitive therapy (CT)- (Specific phobia. http://www. med.upenn.edu).

Progressive desensitization (Specific phobia. http://www. med.upenn.edu).

Relaxation- (Specific phobia. http://www. med.upenn.edu).

Hypnosis (hypnotherapy)- (Natural treatment for phobia and anxiety. http://www.phobicssociety.org)

Homeopathy- (http:// www.phobicssociety.org). Herbal remedies- (Natural treatment for phobia and anxiety. http:// www.phobicssociety.org).

Pharmacotherapy-(Specific phobia. http:// www. med .upenn.edu).

\section{Tips for exam preparation}

The authors suggested the following tips for exam preparation and the precautions to be taken at various stages. These tips will help to reduce the exam phobia.

\section{a) Key Sheet method for Essay questions}

To learn long answers, key sheet method is useful. The following steps are useful for the preparation of essay question answers.

- Write definition

- Write side headings
- Against each side head note important words in such away, by using these words one shall write full essay.

- Practices figures and tables.

Using the key sheet one can quickly revise the syllabus during the exam days. Short answers can also be learnt along with essays, as they are part of it.

\section{b) Planning for Exams}

Since beginning of the academic year, students shall have a systematic planning to reduce the exam phobia.

\section{c) Interesting subjects}

Some students like only some subjects. It is because:

- easy to learn

- opinion formed at lower classes

- teaching good

- positive opinion about the subject teacher

- heredity

\section{d) Tough subjects}

Some students dislike some subjects the reason may be

- feel tough to learn

- opinion formed at lower classes

- unable to understand

- poor teaching genes

- negative opinion about teacher

- heredity

One may like a subject or not, students shall remember thateach subject is important to score good marks. If you spend more time for liking subjects and less time for disliking and tough subjects, the students get less marks.

\section{e) Throughout the year}

- Listen to the lessons carefully

- Understand the lessons

- Clear the doubts

- Write the class notes

- Practicise figures and tables 


\section{f) Before one month from exam date}

- Divide time for all the subjects

- Stick on to the schedule

- Allot more time for tough and disliking subjects

- Take sufficient sleep

- Take care of food

- Do not drink or eat cool food.

\section{g) Before two days from exams}

- Prepare only for first exam

- Revise prepared lessons only

- Do not try to learn new material or lessons

- Take sufficient sleep

- Understand that only preparation is in your hands, not the result

- Maintain happy mood always

\section{h) On the day of Exam}

- Stop preparation at least one hour before the exam

- Get ready with essentials(hall ticket, pen, pencil, eraser etc.,)

- Do not discuss about the subject with friends

- Go to the exam hall at least half an hour before

- Check your pockets if any subject material present. Squads may debar from the exam

\section{i) In the Exam Hall}

- Close your eyes and sit silently for 5 to $10 \mathrm{~min}$

- Write the hall ticket number clearly(if barcode system not necessary)

- Listen to the invigilator's suggestions carefully

- Do not write on the question paper or writing pad

- Read the question paper carefully

- If the question paper is tough do not feel tense, understand that it is tough for others also

- Write the first page slowly and neatly

- Use last page for rough work

- At the end of the exam, check the question numbers and the answers

\section{j) After the Exam}

- Do not discuss about the exam performance

- Take food and rest for some time

- Start preparation for second exam

\section{k) After completion of all the exams}

- Feel that I have done my duty, result is not in my hands

\section{1) After the announcement of results}

- Based on the result take a positive decision about future

- If fails, understand that the education is a part of life only. There are many ways to lead good life. Again there is a chance to write exams and to get success.

- Recall biographies of life winners

- Wise students fight for good future and only fools commit suicide

\section{m) Enjoyment essential}

For getting good marks every student shall play games for half-an-hour to one hour daily. In addition to this, choose at least one extracurricular activity like singing, dancing, and drawing. All these promote physical and mental health positively.

\section{CONCLUSION}

Exam phobia is noticed in many high school students. The present study made a comparison among $8^{\text {th }}$ to $10^{\text {th }}$ students and between rural and urban students. It is concluded that the highest percent of $10^{\text {th }}$ class students are suffering from exam phobia. It is also observed that there is no difference in the phobia between rural and urban students. It is suggested to take an appropriate treatment and to adapt exam preparation tips to reduce exam phobia. 


\section{ACKNOWLEDGEMENT}

Authors are thankful to Rotary club - Adharsh, Guntur Commissioner, GMC and the Authorities of Acharya Nagarjuna University for the financial assistance.

\section{REFERENCES}

[1]. Cassady, J. C. (2001). The stability of undergraduate students' cognitive test anxiety levels. Practical Assessment, Research and Evaluation, 7 (20): 5568.

[2]. Chawla Chanchal, Gupta Sonia And Mahajan Tushar (2013) Examination As A Deterrent: A Case Study On Examination Phobia Among Higher And Senior Secondary Level Students Of Moradabad City, International Journal Of Research In Commerce, Economics \& Management, Volume No. 3, Issue No. 08, Pp. 45-50.

[3]. de Oliveira-Souza R (2018) Phobia of the Supernatural: A Distinct but Poorly Recognized Specific Phobia With an Adverse Impact on Daily Living. Front. Psychiatry 9:590. doi: 10.3389/fpsyt.2018.00590.

[4]. Hanies, J. D., Imeson, and Meade, T. W. (1987). Phobic anxiety and ischemic heart disease. $\mathrm{Br}$ Med J (Clin Res Ed), 295(6593): 297-299.

[5]. Hoffman, Carlin, A., H. G., and Weghorst, S. (1997). Virtual reality in the treatment of spider phobia: a case report. Behavioral Research and Therapy, 35: 153-158.

[6]. Javed Muhammad and Khan Imran (2011), A Survey of Examination Phobia amongst Students at Secondary School Level, Journal of Education and Vocational Research Vol. 1, No. 1, pp. 4-12.

[7]. Kumari Archana And Jain Jagrati (2014), Examination Stress And Anxiety: A Study Of College Students, Global Journal of Multidisciplinary Studies, Volume 4, Issue 01, pp.31-40.

[8]. Mohapatra Samarendra, Sandeep Kumar Panigrahi, Diptirani Rath (2012), Examination Stress in Adolescents, Asian Journal of Paediatric Practice, Vol. 16, No. 1, pp. 7-9..
[9]. Natural treatment for phobia and anxiety. Available at http:// www.phobicssociety .org.uk/naturaltreatmentfor phobiaandanxiety/ Accessed on 24 December 2015.onal Journal of Basic \& C

[10]. Shashank, S. (2008). Health and fitness; Retrieved May 10, 2008 and December 01, 2009 from http://Delhi.quikr.com/f-services-Health-FitnessOQQ Catldz 653 Fitness.

[11]. Singh Jarnail, Singh Janardhan (2016), Treatment options for the specific phobia, Vol 5, Issue 3, pp. 593-598.Inter

[12]. Smita, P. B. (2009). A comparative study of vocational therapy using structured and unstructured instructions in patients with schizophrenia. Eastern Journal of Psychiatry. 1: 8183.

[13]. Specific phobia. Available at http://www. med.upenn.edu/csta/phoias_treatment. html. Accessed on 26 December 2015.

[14]. Stellar, L. (2009). Introducing the new weight loss program. Retrieved February 02, 2009 from http://forum.healthykey.com/2009/111/introducing -the--called-yometrics.htmlnew-loss-weightprogram-calledyometric,www.geocities.com/ frnxty,and http://www.geocities.com/eoa UK.

[15]. Sufiana and Farhat (2015) Examination Phobia among Secondary Level Students, International Research Journal of Arts \& Humanities (IRJAH) Vol. 37, pp.129-146.

[16]. Watson, D., \& Friend, R. (1969). Measurement of social-evaluative anxiety (FNE), Journal of Consulting and Clinical Psychology, 33, 448-457.

[17]. https://www.verywellmind.com/list-of- phobia2795453.

Cite this article as :SankaraPitchaiahPodila , AnjaniThottempudi, "Exam Phobia in Government High School Students, Guntur, Andhra Pradesh, India", International Journal of Scientific Research in Science and Technology (IJSRST), Online ISSN : 2395-602X, Print ISSN : 2395-6011, Volume 6 Issue 1, pp. 100-107, January-February 2019. Available at doi https://doi.org/10.32628/IJSRST196118. 